\title{
Tumour biomechanical response to the vascular disrupting agent ZD6126 in vivo assessed by magnetic resonance elastography
}

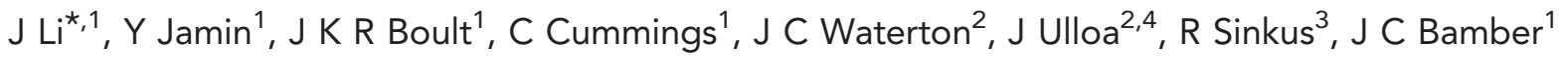 \\ and S P Robinson ${ }^{1}$ \\ ${ }^{1}$ Division of Radiotherapy and Imaging, The Institute of Cancer Research, 15 Cotswold Road, Belmont, Sutton, Surrey SM2 5NG, \\ UK; ${ }^{2}$ Personalised Healthcare and Biomarkers, AstraZeneca, Alderley Park, Macclesfield, Cheshire SK10 4TG, UK and ${ }^{3}$ BHF Centre \\ of Excellence, Division of Imaging Sciences and Biomedical Engineering, King's College London, King's Health Partners, \\ St Thomas' Hospital, London, SE1 7EH, UK
}

Background: Magnetic resonance elastography (MRE) is an emerging imaging technique that affords non-invasive quantitative assessment and visualization of tissue mechanical properties in vivo.

Methods: In this study, MRE was used to quantify (kPa) the absolute value of the complex shear modulus $\left|G^{\star}\right|$, elasticity $G_{d}$ and viscosity $G_{\mid}$of SW620 human colorectal cancer xenografts before and $24 \mathrm{~h}$ after treatment with either $200 \mathrm{mg} \mathrm{kg}^{-1}$ of the vascular disrupting agent ZD6126 ( $\mathrm{N}$-acetylcolchinol-O-phosphate) or vehicle control, and the data were compared with changes in water diffusivity measured by diffusion-weighted magnetic resonance imaging.

Results: A heterogeneous distribution of $\left|G^{*}\right|, G_{d}$ and $G$ was observed pre-treatment with an intertumoral coefficient of variation of $13 \%$ for $\left|G^{\star}\right|$. There were no significant changes in the vehicle-treated cohort. In contrast, ZD6126 induced a significant decrease in the tumour-averaged $\left|G^{\star}\right|(P<0.01), G_{d}(P<0.01)$ and $G_{\mid}(P<0.05)$, and this was associated with histologically confirmed central necrosis. This reduction in tumour viscoelasticity occurred at a time when no significant change in tumour apparent diffusion coefficient (ADC) was observed.

Conclusions: These data demonstrate that MRE can provide early imaging biomarkers for treatment-induced tumour necrosis.

The ultimate aim of cancer therapeutics is to elicit a cytotoxic response, causing tumours to disappear ('Response'), or a cytolentic effect that prevents tumour progression ('Stable Disease'), prolonging patient overall survival. While these can be assessed using imaging biomarkers, notably the response criteria in solid tumours (RECIST); many drugs, and in particular many novel tumour targeted therapies, must be administered for several months before RECIST can be applied
(Michaelis and Ratain, 2006). Drug developers seek pharmacodynamic biomarkers that can determine rapidly (ideally in hours or days) whether the drug has had the desired biological effect on the tumour, before RECIST changes are evident; or alternatively that the drug or dose has no biological effect, and is therefore either unsuitable for specific patients (stratified medicine), or indeed should be discontinued from drug development for lack of efficacy.

\footnotetext{
*Correspondence: J Li; E-mail: Jin.Li@icr.ac.uk

${ }^{4}$ Current Address: Bioxydyn Limited, Manchester, UK.
} 
Imaging biomarkers for assessing tumour pathophysiology and response are continually being sought, and such biomarkers require evaluation before they can be deployed in clinical trials (Boult et al, 2012; Waterton and Pylkkanen, 2012). With the new generation of targeted cancer therapeutics has come the need to investigate other emerging, more specific, biomarkers of cell death provided by imaging methods. These may further aid in interpretation and provide additional data to help characterize other key hallmarks of tumour pathophysiology before, during and following a pharmacological response.

Historically, palpation has been used clinically to detect the presence of abnormal tissue in superficial or accessible lesions in vivo, as diseased tissues can be identified by differences in tissue stiffness. The altered stiffness associated with tumours is a hallmark of cancer, and primarily reflects increased matrix rigidity linked to fibrosis, stress associated with rapid tissue expansion and compressed vasculature and lymphatics, and possibly an increase in the viscoelasticity of transformed cells through cytoskeletal tension (Heldin et al, 2004; Paszek et al, 2005). Innovative imaging techniques are being exploited to non-invasively image the mechanical or viscoelastic properties of tissue in vivo. Specifically, magnetic resonance elastography (MRE) has been used to directly visualize dynamic tissue strain following application of a vibrational mechanical stress to that tissue in vivo (Muthupillai and Ehman, 1996) and thus measure the shear elastic modulus of the tissue without the need for administration of an exogenous contrast agent. Several studies have since highlighted the potential of MRE using commercially available mechanical drivers for the diagnosis and staging of cancer in the clinic, and as a prognostic indicator (Sinkus et al, 2000; Lorenzen et al, 2002; Yeung et al, 2013).

A useful pharmacodynamic has good inter- and intrasubject reproducibility, while exhibiting rapid and marked responses to previously described interventions that are known to elicit the desired biological change (Waterton, 2013). We hypothesized that large-scale changes in tissue morphology induced by necrosis are associated with significant alterations in tissue macroscopic viscoelastic properties. Therefore, measuring changes in viscoelastic properties of tumours with MRE may provide novel imaging biomarkers of treatment response. To test this, we have implemented preclinical MRE on a $7 \mathrm{~T}$ magnetic resonance imaging (MRI) platform, and evaluated viscosity and elasticity as imaging biomarkers of pharmacologically induced tumour necrosis in a murine xenograft model. Tumour necrosis was induced $24 \mathrm{~h}$ after treatment with the vascular disrupting agent ZD6126 ( $N$-acetylcolchinol-O-phosphate; Blakey et al, 2002a, b). The MRE response was compared with treatment-induced changes in the tumour apparent diffusion coefficient (ADC), a more established imaging biomarker of cell death (Sinkus et al, 2012) and of tumour response in the clinic (Koh et al, 2009), and validated by pathological correlates.

\section{MATERIALS AND METHODS}

Animals and tumours. All experiments were performed in compliance with licences issued under the UK Animals (Scientific Procedures) Act 1986 following local ethical review, and with the United Kingdom National Cancer Research Institute guidelines for the welfare of animals in cancer research (Workman et al, 2010). SW620 human colorectal carcinoma cells $\left(5 \times 10^{6}\right)$ were implanted subcutaneously in the flanks of female NCr nude mice. For MRI and MRE, anaesthesia was induced with a $10 \mathrm{mg} \mathrm{ml}^{-1}$ intraperitoneal injection of fentanyl citrate $\left(0.315 \mathrm{mg} \mathrm{ml}^{-1}\right)$ plus fluanisone $\left(10 \mathrm{mg} \mathrm{ml}^{-1}\right)$ ('Hypnorm'; Janssen Pharmaceutical Ltd, High Wycombe, UK), midazolam $\left(5 \mathrm{mg} \mathrm{ml}^{-1}\right)$ ('Hypnovel';
Roche, Burgess Hill, UK) and water (1:1:2). Tumour growth was monitored, and tumour volume was determined using callipers and assuming an ellipsoid shape (volume $(\pi / 6) \times L \times W \times D$, where $L, W$ and $D$ are the largest orthogonal dimensions of the ellipsoid).

Formulation, administration and dosing of ZD6126. ZD6126 (Angiogene Pharmaceuticals, Oxford, UK) is a vascular disrupting agent shown to induce extensive central tumour necrosis in a wide range of murine models $24 \mathrm{~h}$ after a single dose of $200 \mathrm{mg} \mathrm{kg}^{-1}$ (Blakey et al, 2002a, b; Davis et al, 2002). ZD6126 was formulated in $20 \%$ of $5 \%$ sodium carbonate and $80 \%$ phosphate-buffered saline, and was administered intraperitoneally to the mice. Control mice were treated with vehicle alone.

MRI and MRE data acquisition. All data were acquired from anaesthetized mice on a $7 \mathrm{~T}$ horizontal bore MicroImaging MRI system (Bruker Instruments, Ettlingen, Germany) using a $3 \mathrm{~cm}$ birdcage coil. Mouse core temperature was maintained at $\sim 37^{\circ} \mathrm{C}$ with warm air blown through the magnet bore. An electromagnetic shaker (Brüel \& Kjaer, Nærum, Denmark) was used to generate mechanical vibration, which was directly transmitted through a flexible nylon rod to a square semicurved piston positioned onto the tumour within the coil at the magnet isocentre. The horizontal vibration of the shaker and the rod were converted into vertical vibrations via a cantilever (Figure 1).

Anatomical $\mathrm{T}_{2}$-weighted images were first acquired, using a rapid acquisition with refocused echoes (RARE) sequence, with $\mathrm{TE}=36 \mathrm{~ms}, \mathrm{TR}=4.5 \mathrm{~s}$ and a RARE factor of 8 . Images were acquired from 40 contiguous 1 -mm-thick transverse slices, with 1 average of 128 phase-encoding steps over a $3 \times 3 \mathrm{~cm}$ field of view (FOV). The total acquisition time was $53 \mathrm{~s}$. These images were used for determining tumour volumes, planning of the MRE acquisition and included optimization of the local field homogeneity over the region of interest (FASTMAP; Bruker Instruments).

Subsequently, a two-dimensional spin-echo sequence was applied with a mechanical excitation at a vibration frequency of $1000 \mathrm{~Hz}$, which generates mechanical waves inside the tumour with amplitude $>0.3 \mu \mathrm{m}$ and three times the noise level (Juge et al, 2012). The spin-echo sequence was modified with sinusoidal motion-sensitizing gradients synchronized to the mechanical excitation. Data were acquired in three gradient directions, from 10 contiguous transverse slices at $300 \mu \mathrm{m}$ intervals, using 2 averages of 64 phase-encoding steps over a $1.92 \times 1.92 \mathrm{~cm}$ FOV, with $\mathrm{TE}=27 \mathrm{~ms}, \mathrm{TR}=1001 \mathrm{~ms}$ and 8 time steps, giving an isotropic spatial sampling of $300 \times 300 \times 300 \mu \mathrm{m}$ of the mechanical wave propagation displacement inside the tumour. The total acquisition time was $\sim 51 \mathrm{~min}$.

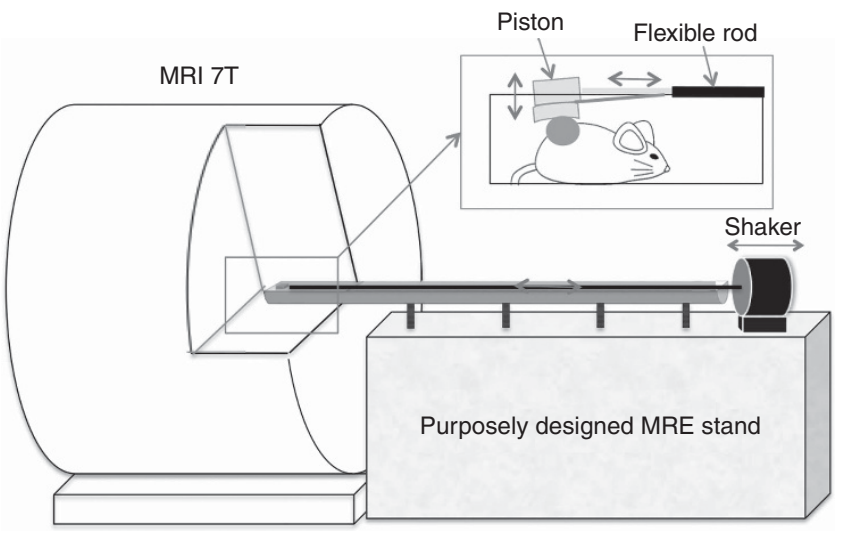

Figure 1. Schematic showing the MRE platform developed for this study. 
High-resolution anatomical $\mathrm{T}_{2}$-weighted images were then acquired from the same 10 contiguous transverse slices, using a RARE sequence with 10 averages of 128 phase-encoding steps over the same $1.92 \times 1.92 \mathrm{~cm}$ FOV $(150 \times 150 \mu \mathrm{m}$ in plane resolution $)$, with $\mathrm{TE}=36 \mathrm{~ms}, \mathrm{TR}=4.5 \mathrm{~s}$ and a RARE factor of 8 . The total acquisition time was $\sim 9 \mathrm{~min}$. Finally, an echo-planar diffusionweighted sequence $(\mathrm{TR}=1500 \mathrm{~ms}, \quad b$-values $=200,500$ and $700 \mathrm{~s} \mathrm{~mm}^{-2}$, 1 average, FOV $1.92 \times 1.92 \mathrm{~cm}$, matrix size $64 \times 64$ ) was then used to determine the tumour ADC from three contiguous $600-\mu \mathrm{m}$-thick transverse slices through the centre of the tumour. The total acquisition time was $\sim 3 \mathrm{~min}$.

Magnetic resonance imaging was performed on mice bearing size-matched SW620 xenografts ( $\sim 1 \mathrm{~cm}$ diameter) before and $24 \mathrm{~h}$ after treatment with either ZD6126 $(n=4)$ or vehicle alone $(n=6)$. Care was taken in positioning the animal so as to acquire MRE data from the same tumour location before and after treatment.

Image reconstruction and analysis. Images of the absolute value of the complex shear modulus $\left|G^{*}\right|$, elasticity $G_{\mathrm{d}}$ and viscosity $G_{\mathrm{l}}$ (where $G^{*}=G_{\mathrm{d}}+i G_{\mathrm{l}}$ ) were reconstructed with an isotropic voxel size of $300 \mu \mathrm{m}$, from the three-dimensional displacement vector measured as described above, using the following equation (Sinkus et al, 2007):

$$
-\rho \omega^{2} \vec{q}=G^{*} \nabla^{2} \vec{q}, \vec{q}=\vec{\nabla} \times \vec{u} \in C^{3},
$$

where $\vec{q}$ is the complex-valued curl of the displacement field $\vec{u}, \rho$ is the density of the material and $\omega$ the angular frequency. For each slice, $\left|G^{\star}\right|, G_{\mathrm{d}}$ and $G_{\mathrm{l}}(\mathrm{kPa})$ were determined pixelwise from a region of interest covering the whole tumour identified from $\mathrm{T}_{2}$-weighted imaging, including both the viable and necrotic tissue. In addition, the shear wave speed, $c_{\mathrm{s}}\left(\mathrm{m} \mathrm{s}^{-1}\right)$, and the attenuation coefficient, $\alpha\left(1 \mathrm{~mm}^{-1}\right)$, were calculated with the mean values determined from the same region of interest (Sinkus et al, 2007).

Diffusion-weighted data were fitted monoexponentially on a pixel-by-pixel basis using in-house software (ImageView, developed in IDL; ITT Visual Information Systems, Boulder, CO, USA), using a Bayesian maximum a posteriori approach that took into account the Rician distribution of noise in magnitude MR data, and provided estimates of the ADC, allowing the median value for each tumour to be determined (Walker-Samuel et al, 2011; Baker et al, 2012).

Histological analysis. After the final imaging session, tumours were excised, cut in the same orientation as the MRI, fixed in formalin and embedded in paraffin wax. Subsequently, tissue sections were cut and stained with haematoxylin and eosin (H\&E) for the assessment of necrosis.

Statistical analysis. Results are presented in the form mean \pm 1 s.e.m. In significance testing, Student's two-tailed $t$-test was used, assuming unequal variance with a $5 \%$ level of significance. A paired $t$-test was used for comparison of results before and after treatment, and an unpaired $t$-test was used for comparison between vehicle control and treated cohorts.

\section{RESULTS}

Pre-treatment MRE revealed a heterogeneous distribution of $\left|G^{\star}\right|$, $G_{\mathrm{d}}$ and $G_{1}$ throughout each SW620 xenograft (Figure 2). There was no apparent change in viscoelasticity in the vehicle control cohort after $24 \mathrm{~h}$ of administration with vehicle (coefficient of variation of $\left.\left|G^{*}\right|=13 \%\right)$. In contrast, treatment with ZD6126 resulted in a marked decrease and a visually evident more homogeneous distribution of $\left|G^{*}\right|, G_{\mathrm{d}}$ and $G_{\mathrm{l}}$ (maps of $G_{\mathrm{d}}$ and $G_{1}$ not shown) within the central region of the tumour. Maps of $\left|G^{\star}\right|$ from two representative tumours either treated with ZD6126 or vehicle are shown in Figure $3 \mathrm{~A}$ and B. Interestingly, $\left|G^{*}\right|$ was largely unchanged in the tumour rim after challenge with ZD6126. Normalized frequency histograms obtained from the same tumour before and after administration of ZD6126 revealed a clear shift towards lower $\left|G^{\star}\right|$ following treatment, whereas vehicle-treated tumours showed a slight shift towards higher $\left|G^{*}\right|$ (Figures 3C and D). Representative H\&E-stained sections of SW620 tumours $24 \mathrm{~h}$ after treatment with either vehicle or ZD6126 are shown in Figures 3E and F. ZD6126 caused extensive central haemorrhagic necrosis, with a viable rim of tumour remaining.

Tumour ADC maps showed no apparent changes at $24 \mathrm{~h}$ after treatment with ZD6126 (Figure 4B). Mean values of tumour volume, $\left|G^{*}\right|, G_{\mathrm{d}}, G_{1}$ and ADC from the vehicle and ZD6126treated cohorts are summarized in Table 1. There was no significant difference in tumour volume following treatment with either vehicle or ZD6126. Whilst there was no significant change in any parameters in the vehicle-treated group, the mechanical parameters $\left|G^{\star}\right|, G_{\mathrm{d}}$ and $G_{1}$ were all significantly reduced in the ZD6126-treated cohort. The ADC increased in each of the ZD6126-treated tumours (Figure 4C), although the change in mean ADC was not significant. A more direct comparison of the relative change in tumour volume, $\mathrm{ADC},\left|G^{*}\right|, c_{\mathrm{s}}$ and $\alpha$, was determined $24 \mathrm{~h}$ after treatment with either vehicle or $200 \mathrm{mg} \mathrm{kg}^{-1}$ ZD6126, and is shown in Figure 4D. The clear and highly significant ZD6126-induced reduction in $\left|G^{\star}\right|$ and $\mathcal{C}_{\mathrm{s}}$, and significant increase in $\alpha$, which were significantly different from the behaviour of the vehicle group, were associated with a nonsignificant increase in ADC at this time point.

\section{DISCUSSION}

Non-invasive quantitative imaging biomarkers are essential for assessing tumour pathophysiology and response to novel targeted therapeutics. Before deployment in clinical trials, such imaging biomarkers require qualification, typically through preclinical identification of imaging-pathology correlates, to confirm whether changes in the imaging biomarker reflect predicted changes in the underlying pathology. Increased tissue stiffness is often associated with an invasive and malignant tumour phenotype (Paszek et al, 2005; Dvorak et al, 2011). Elastography, and MRE in particular, is an emerging imaging technique being used to measure tissue
A

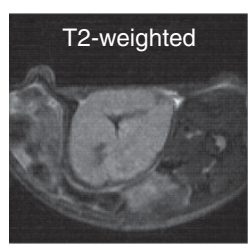

B

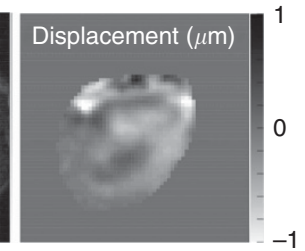

C

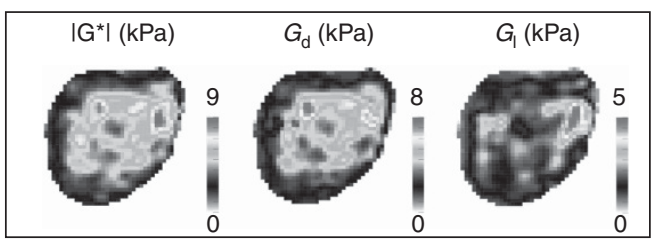

Figure 2. Magnetic resonance images and calculated MRE parameter maps from one representative pre-treatment SW620 xenograft. (A) Anatomical $\mathrm{T}_{2}$-weighted MR image, (B) displacement $(\mu \mathrm{m})$ image derived from phase information acquired during the MRE acquisition, illustrating wave propagation at $1000 \mathrm{~Hz}$ and $(\mathbf{C})$ calculated maps of $\left|G^{*}\right|, G_{d}$ and $G_{\text {l }}$ before treatment. 
A

$\left|G^{*}\right|(\mathrm{kPa})$
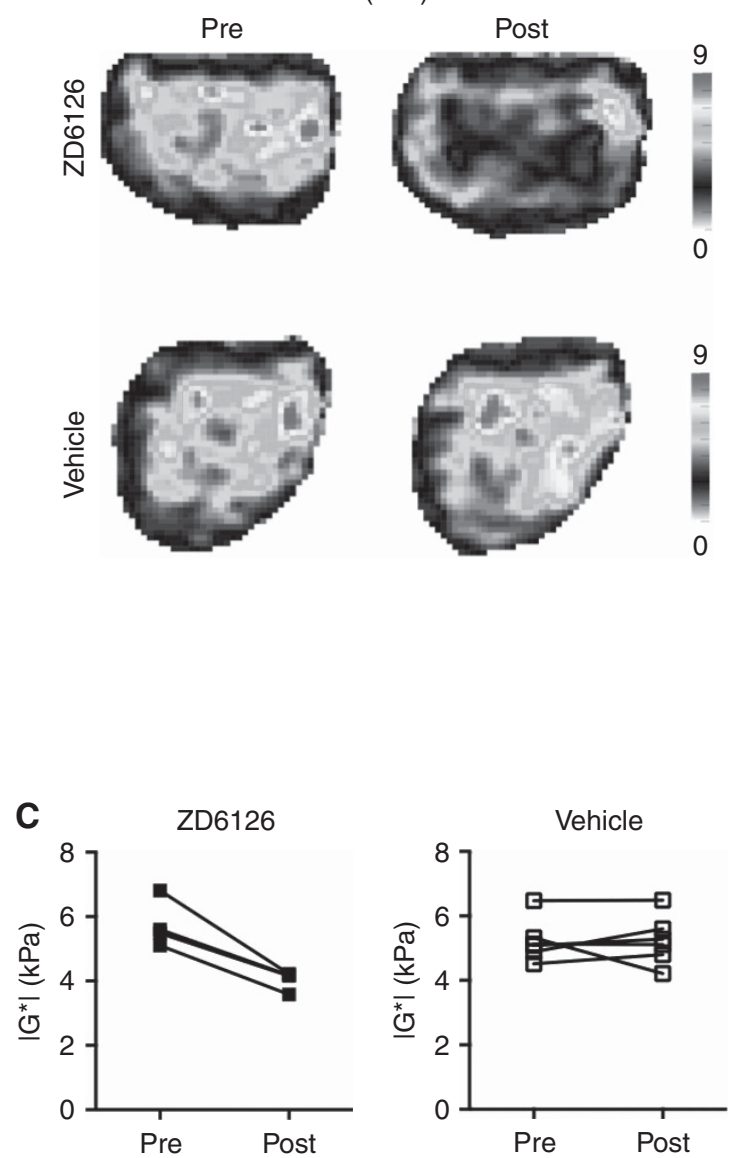
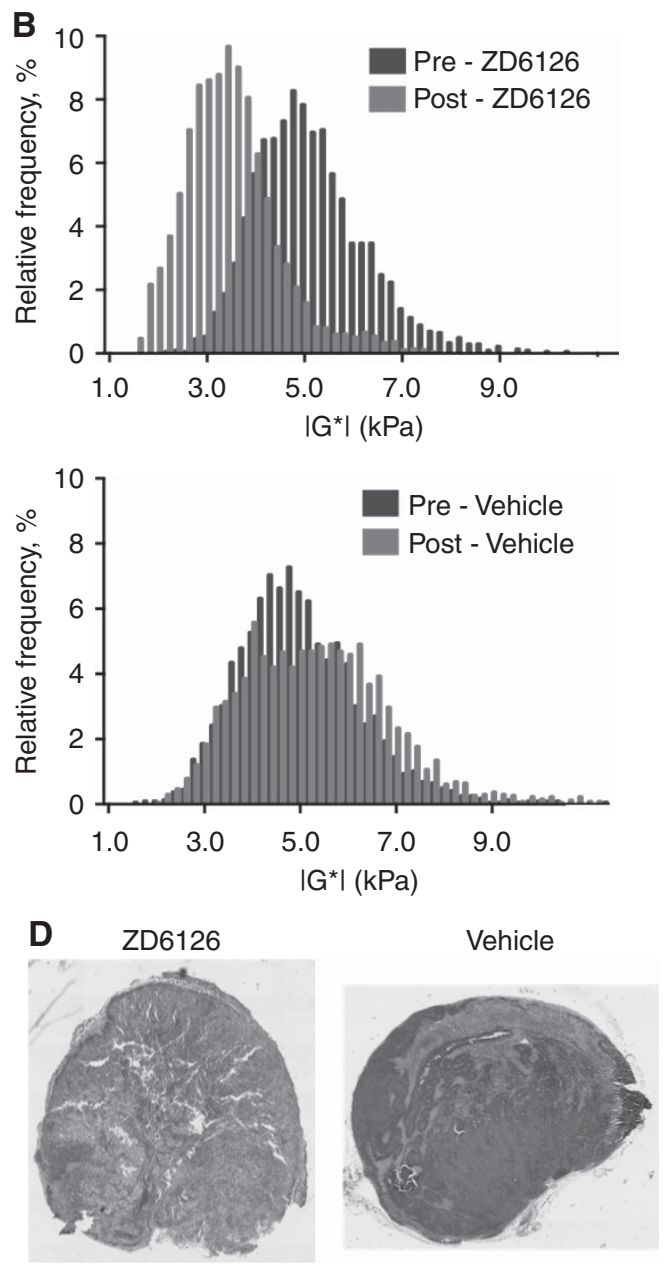

Figure 3. (A) Calculated maps of $\left|G^{\star}\right|$ from two representative SW620 xenografts before and $24 \mathrm{~h}$ after treatment with $200 \mathrm{mg} \mathrm{kg}^{-1} \mathrm{ZD} 6126$ or vehicle alone. (B) Frequency histograms of $\left|G^{*}\right|$ acquired from the same tumours shown in (A) before and following treatment. (C) Ladder plot of individual response in $\left|G^{\star}\right|$ of all SW620 xenografts to $200 \mathrm{mg} \mathrm{kg}^{-1}$ ZD6126 or vehicle. (D) Haematoxylin and eosin stained sections obtained from SW620 xenografts $24 \mathrm{~h}$ after treatment with $200 \mathrm{mg} \mathrm{kg}^{-1}$ ZD6126 or vehicle.
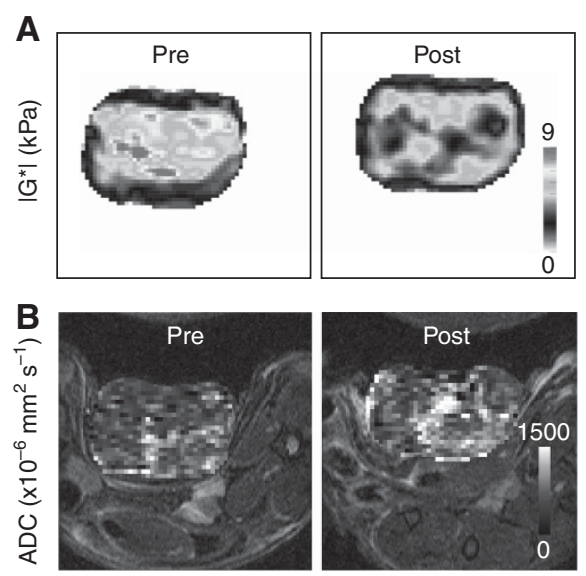

D
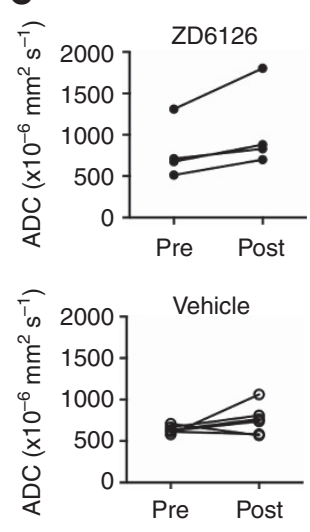

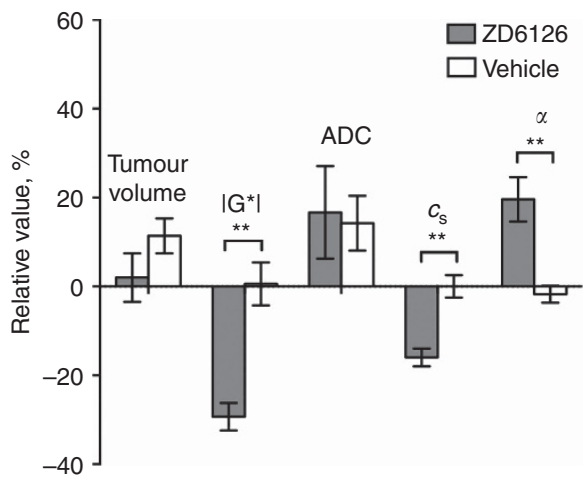

Figure 4. Calculated maps of (A) $\left|G^{*}\right|$ and (B) ADC determined from one representative SW620 xenograft before and $24 \mathrm{~h}$ after treatment with $200 \mathrm{mg} \mathrm{kg}^{-1}$ ZD6126. (C) Ladder plot of the individual responses in ADC of all SW620 xenografts to $200 \mathrm{mg} \mathrm{kg}^{-1} \mathrm{ZD} 126$ or vehicle. (D) Relative changes in tumour volume, $\left|G^{\star}\right|, A D C$, shear wave speed $c_{s}$ and attenuation coefficient $\alpha$ over $24 \mathrm{~h}$ in the vehicle- or ZD6126-treated cohorts. Data are mean \pm 1 s.e.m., ${ }^{\star *} P<0.01$, Student's two-tailed unpaired $t$-test between treated and vehicle.

mechanical properties in vivo, and has shown promise in cancer diagnosis (Siegmann et al, 2010; Garteiser et al, 2012; Sahebjavaher et al, 2013). The overall aim of this study was to evaluate viscosity and elasticity as imaging biomarkers of response to the vascular disrupting agent ZD6126 in SW620 colorectal murine xenografts. 
Table 1. Summary of the volume, complex shear modulus $\left|G^{\star}\right|$, elasticity $G_{d}$, viscosity $G_{l}$ and $A D C$ determined in SW620 xenografts before and $24 \mathrm{~h}$ after treatment with either vehicle or $200 \mathrm{mg} \mathrm{kg}^{-1}$ ZD6126

\begin{tabular}{|c|c|c|c|c|}
\hline & \multicolumn{2}{|c|}{ Vehicle $(n=6)$} & \multicolumn{2}{|c|}{ ZD6126 $(n=4)$} \\
\hline & Pre & Post & Pre & Post \\
\hline Volume $\left(\mathrm{mm}^{3}\right)$ & $408 \pm 78$ & $450 \pm 77$ & $430 \pm 40$ & $440 \pm 54$ \\
\hline$\left|G^{\star}\right|(\mathrm{kPa})$ & $5.24 \pm 0.27$ & $5.25 \pm 0.31$ & $5.75 \pm 0.37$ & $4.04 \pm 0.15^{\star \star}$ \\
\hline$G_{d}(\mathrm{kPa})$ & $4.30 \pm 0.17$ & $4.35 \pm 0.19$ & $4.92 \pm 0.27$ & $3.44 \pm 0.13^{\star \star}$ \\
\hline $\mathrm{G}_{\mathrm{l}}(\mathrm{kPa})$ & $2.40 \pm 0.24$ & $2.38 \pm 0.25$ & $2.47 \pm 0.21$ & $1.72 \pm 0.07^{\star}$ \\
\hline $\operatorname{ADC}\left(\times 10^{-6} \mathrm{~mm}^{2} \mathrm{~s}^{-1}\right)$ & $637 \pm 18$ & $754 \pm 73$ & $675 \pm 36$ & $950 \pm 152$ \\
\hline \multicolumn{5}{|c|}{$\begin{array}{l}\text { Abbreviations: } A D C=\text { apparent diffusion coefficient; } Z D 6126=N \text {-acetylcolchinol-O-phos- } \\
\text { phate. Data values are mean } \pm 1 \text { s.e.m., where }{ }^{*} P<0.05 \text { and }{ }^{*} P<0.01 \text { indicate significant } \\
\text { results of a Student's two-tailed paired t-test between the post- and pre-treatment values. } \\
\text { Values for }\left|G^{\star}\right|, G_{d}, G \text { and } A D C \text { were obtained as mean values from the whole tumour area } \\
\text { in a representative central section, after which means and s.e.'s were computed over the } \\
\text { cohort. }\end{array}$} \\
\hline
\end{tabular}

Magnetic resonance elastography pre-treatment revealed a typically heterogeneous distribution of $\left|G^{*}\right|, G_{\mathrm{d}}$ and $G_{1}$ across all the tumours, and good reproducibility over $24 \mathrm{~h}$ in the vehicletreated cohort. The mean $\left|G^{\star}\right|$ for the SW620 colorectal xenografts of $5.4 \mathrm{kPa}$ was in good agreement with $4.0 \mathrm{kPa}$ recently reported in ectopically propagated murine colon 26 tumours (Juge et al, 2012).

ZD6126 is a prodrug of the tubulin-binding agent $\mathrm{N}$-acetylcolchinol that inhibits tubulin polymerization, disrupting the cytoskeleton of proliferating tumour vascular endothelial cells, leading to endothelial cell detachment, tumour vessel occlusion and ultimately massive central necrosis. Numerous studies have reported significant antivascular activity, and subsequent necrosis, in murine and human tumour models $24 \mathrm{~h}$ after a single $200 \mathrm{mg} \mathrm{kg}^{-1}$ dose of ZD6126 (Blakey et al, 2002b; Cullis et al, 2006). This dose regimen induced a significant reduction in $\left|G^{*}\right|$, $G_{\mathrm{d}}, G_{\mathrm{l}}$ and shear wave speed $c_{\mathrm{s}}$, and a significant increase in attenuation, $\alpha$, of SW620 xenografts in vivo, independent of tumour growth, and was associated with reduced tissue integrity and necrosis as confirmed by histology. A characteristic feature of tumour response to a vascular disrupting agent is the existence of a surviving rim of tumour cells following treatment, from which the tumour continues to grow (Tozer et al, 2005). The relatively higher $\left|G^{*}\right|$ observed in the periphery of the SW620 xenografts after treatment with ZD6126 herein is consistent with this viable rim, and further emphasizes that extensive necrosis contributes to the decrease in tumour mechanical properties measured by MRE. A significant reduction in $\left|G^{*}\right|$ was reported in subcutaneous murine colon 26 tumours $24 \mathrm{~h}$ after treatment with combretastatin A4 phosphate (CA4P), which was associated with a reduction in microvessel density, suggesting that the complex shear modulus is influenced by vascular architecture (Juge et al, 2012).

More recently, MRE using shear waves generated by a needle inserted directly into the tumour revealed a significant decrease in $\left|G^{*}\right|$ in subcutaneous DoHH2 lymphoma xenografts following chemotherapy, which was associated with decreased levels of cellular proliferation (Pepin et al, 2013). The non-invasive activepassive driver system used herein for generating shear waves is advantageous in retaining tissue integrity, with no local perturbation of the tumour microenvironment that could influence $\left|G^{\star}\right|$.

Treatment with ZD6126 was seen here to result in a reduction in shear wave speed and an increase in the shear wave attenuation coefficient. Further work is needed to understand the mechanisms for these drug-induced changes to the shear wave tissue characteristics. However, it is known that shear stress relaxes over very short distances and very rapidly in liquids. Therefore, the propagation of a shear wave through the tissue most likely occurs through the extracellular structural matrix, the vasculature and by cells being in very close proximity to each other (Bamber et al, 2013). Necrosis may alter shear wave propagation by its effect on any of these structural components. Necrosis is also associated with a loss of cell integrity (and thus cell elasticity and cell contact with other cells and with the matrix), and a general increase in the free liquid content of the tissue. The more liquid that a shear wave must cross, the more it will be attenuated. These effects may also produce a softer integrated tissue path and thus a reduced shear wave speed.

Quantification of tumour ADC using diffusion-weighted MRI is being actively exploited as an imaging biomarker of tumour response (Padhani et al, 2009; Sinkus et al, 2012). In viable tumour tissue containing intact cell membranes, tight junctions, macromolecules and organelles, the movement of water molecules is hindered, resulting in reduced water diffusion. The reduction of cell membrane integrity and density associated with treatmentinduced tumour necrosis typically results in an increase in ADC. Despite the clear reduction in viscoelastic properties, no significant increase in ADC in SW620 xenografts was found $24 \mathrm{~h}$ after treatment with a single dose of $200 \mathrm{mg} \mathrm{kg}^{-1}$ ZD6126. In a human prostate cancer model, DU-145 subcutaneous xenograft, a significant increase in ADC has been reported, but at $48 \mathrm{~h}$ after treatment using an identical dose regimen (Vogel-Claussen et al, 2007). A significant increase in ADC was observed in murine colon 26 tumours $24 \mathrm{~h}$ after treatment with CA4P, which was associated with increased necrosis (Juge et al, 2012). It is important to note that the maximal vascular disrupting activity of CA4P in tumours occurs typically $6 \mathrm{~h}$ after drug administration, whereas for ZD6126 this arises $\sim 24 \mathrm{~h}$ after treatment (Horsman and Siemann, 2006). This may provide an explanation for the subsequent difference in temporal ADC response for these two vascular disrupting agents. The significant decrease in $\left|G^{\star}\right| 24 \mathrm{~h}$ after treatment with ZD6126 suggests that changes in tissue viscoelastic properties, as measured by MRE, can provide more acute and sensitive imaging biomarkers for the detection of therapy-induced tumour necrosis.

In conclusion, $\left|G^{*}\right|, G_{\mathrm{d}}$ and $G_{\mathrm{l}}$, quantified by MRE, provide early imaging biomarkers for the detection of massive central tumour necrosis following treatment with the vascular disrupting agent ZD6126, and which preceded any significant change in tumour ADC. The use of a drug that elicits a well-described tumour response such as ZD6126 provides a strong basis for the further evaluation of MRE in xenograft mouse models of cancer, and for the assessment of tumour response to novel molecularly targeted therapeutics, and drugs that specifically target the mechanical properties of the matrix environment.

\section{ACKNOWLEDGEMENTS}

We acknowledge support from a Dorothy Hodgkin Postgraduate Award (DHPA) EP/P505828/1, AstraZeneca, The Institute of Cancer Research Cancer Research UK and EPSRC Cancer Imaging Centre, in association with the MRC and Department of Health (England) Grants C1060/A10334, NHS funding to the NIHR Biomedical Research Centre and The Wellcome Trust Grant No. 091763Z/10/Z.

\section{REFERENCES}

Baker LC, Boult JK, Walker-Samuel S, Chung YL, Jamin Y, Ashcroft M, Robinson SP (2012) The HIF-pathway inhibitor NSC-134754 induces metabolic changes and anti-tumour activity while maintaining vascular function. Br J Cancer 106(10): 1638-1647. 
Bamber J, Cosgrove D, Dietrich CF, Fromageau J, Bojunga J, Calliada F, Cantisani V, Correas JM, D’Onofrio M, Drakonaki EE, Fink M, Friedrich-Rust M, Gilja OH, Havre RF, Jenssen C, Klauser AS, Ohlinger R, Saftoiu A, Schaefer F, Sporea I, Piscaglia F (2013) EFSUMB Guidelines and Recommendations on the Clinical Use of Ultrasound Elastography. Part 1: basic principles and technology. Ultraschall Med 34(2): 169-184.

Blakey DC, Ashton SE, Westwood FR, Walker M, Ryan AJ (2002a) ZD6126: a novel small molecule vascular targeting agent. Int J Radiat Oncol Biol Phys 54(5): 1497-1502.

Blakey DC, Westwood FR, Walker M, Hughes GD, Davis PD, Ashton SE, Ryan AJ (2002b) Antitumor activity of the novel vascular targeting agent ZD6126 in a panel of tumor models. Clin Cancer Res 8(6): 1974-1983.

Boult JK, Jamin Y, Jacobs V, Gilmour LD, Walker-Samuel S, Halliday J, Elvin P, Ryan AJ, Waterton JC, Robinson SP (2012) False-negative MRI biomarkers of tumour response to targeted cancer therapeutics. Br J Cancer 106(12): 1960-1966.

Cullis ER, Kalber TL, Ashton SE, Cartwright JE, Griffiths JR, Ryan AJ, Robinson SP (2006) Tumour overexpression of inducible nitric oxide synthase (iNOS) increases angiogenesis and may modulate the antitumour effects of the vascular disrupting agent ZD6126. Microvasc Res 71(2): 76-84.

Davis PD, Dougherty GJ, Blakey DC, Galbraith SM, Tozer GM, Holder AL, Naylor MA, Nolan J, Stratford MR, Chaplin DJ, Hill SA (2002) ZD6126: a novel vascular-targeting agent that causes selective destruction of tumor vasculature. Cancer Res 62(24): 7247-7253.

Dvorak HF, Weaver VM, Tlsty TD, Bergers G (2011) Tumor microenvironment and progression. J Surg Oncol 103(6): 468-474.

Garteiser P, Doblas S, Daire JL, Wagner M, Leitao H, Vilgrain V, Sinkus R, Van Beers BE (2012) MR elastography of liver tumours: value of viscoelastic properties for tumour characterisation. Eur Radiol 22(10): 2169-2177.

Heldin CH, Rubin K, Pietras K, Ostman A (2004) High interstitial fluid pressure - an obstacle in cancer therapy. Nat Rev Cancer 4(10): 806-813.

Horsman MR, Siemann DW (2006) Pathophysiologic effects of vasculartargeting agents and the implications for combination with conventional therapies. Cancer Res 66(24): 11520-11539.

Juge L, Doan BT, Seguin J, Albuquerque M, Larrat B, Mignet N, Chabot GG, Scherman D, Paradis V, Vilgrain V, Van Beers BE, Sinkus R (2012) Colon tumor growth and antivascular treatment in mice: complementary assessment with MR elastography and diffusion-weighted MR imaging. Radiology 264(2): 436-444.

Koh DM, Blackledge M, Collins DJ, Padhani AR, Wallace T, Wilton B, Taylor NJ, Stirling JJ, Sinha R, Walicke P, Leach MO, Judson I, Nathan P (2009) Reproducibility and changes in the apparent diffusion coefficients of solid tumours treated with combretastatin A4 phosphate and bevacizumab in a two-centre phase I clinical trial. Eur Radiol 19(11): 2728-2738.

Lorenzen J, Sinkus R, Lorenzen M, Dargatz M, Leussler C, Roschmann P, Adam G (2002) MR elastography of the breast:preliminary clinical results. Rofo 174(7): 830-834.

Michaelis LC, Ratain MJ (2006) Measuring response in a post-RECIST world: from black and white to shades of grey. Nat Rev Cancer 6(5): 409-414.

Muthupillai R, Ehman RL (1996) Magnetic resonance elastography. Nat Med 2(5): 601-603.

Padhani AR, Liu G, Koh DM, Chenevert TL, Thoeny HC, Takahara T, Dzik-Jurasz A, Ross BD, Van Cauteren M, Collins D, Hammoud DA, Rustin GJ, Taouli B, Choyke PL (2009) Diffusion-weighted magnetic resonance imaging as a cancer biomarker: consensus and recommendations. Neoplasia 11(2): 102-125.

Paszek MJ, Zahir N, Johnson KR, Lakins JN, Rozenberg GI, Gefen A, Reinhart-King CA, Margulies SS, Dembo M, Boettiger D, Hammer DA, Weaver VM (2005) Tensional homeostasis and the malignant phenotype. Cancer Cell 8(3): 241-254.

Pepin KM, Chen J, Glaser KJ, Mariappan YK, Reuland B, Ziesmer S, Carter R, Ansell SM, Ehman RL, McGee KP (2013) MR elastography derived shear stiffness - a new imaging biomarker for the assessment of early tumor response to chemotherapy. Magn Reson Med; e-pub ahead of print 25 June 2013; doi:10.1002/mrm.24825.

Sahebjavaher RS, Baghani A, Honarvar M, Sinkus R, Salcudean SE (2013) Transperineal prostate MR elastography: initial in vivo results. Magn Reson Med 69(2): 411-420.

Siegmann KC, Xydeas T, Sinkus R, Kraemer B, Vogel U, Claussen CD (2010) Diagnostic value of MR elastography in addition to contrast-enhanced MR imaging of the breast-initial clinical results. Eur Radiol 20(2): 318-325.

Sinkus R, Lorenzen J, Schrader D, Lorenzen M, Dargatz M, Holz D (2000) High-resolution tensor MR elastography for breast tumour detection. Phys Med Biol 45(6): 1649-1664.

Sinkus R, Siegmann K, Xydeas T, Tanter M, Claussen C, Fink M (2007) MR elastography of breast lesions: understanding the solid/liquid duality can improve the specificity of contrast-enhanced MR mammography. Magn Reson Med 58(6): 1135-1144.

Sinkus R, Van Beers BE, Vilgrain V, DeSouza N, Waterton JC (2012) Apparent diffusion coefficient from magnetic resonance imaging as a biomarker in oncology drug development. Eur J Cancer 48(4): 425-431.

Tozer GM, Kanthou C, Baguley BC (2005) Disrupting tumour blood vessels. Nat Rev Cancer 5(6): 423-435.

Vogel-Claussen J, Gimi B, Artemov D, Bhujwalla ZM (2007) Diffusionweighted and macromolecular contrast enhanced MRI of tumor response to antivascular therapy with ZD6126. Cancer Biol Ther 6(9): 1469-1475.

Walker-Samuel S, Orton M, Boult JK, Robinson SP (2011) Improving apparent diffusion coefficient estimates and elucidating tumor heterogeneity using Bayesian adaptive smoothing. Magn Reson Med 65(2): 438-447.

Waterton JC (2013) Translational magnetic resonance imaging and spectroscopy: opportunities and challenges. In: New Applications of NMR in Drug Discovery and Development, Chapter 12, pp 333-360. The Royal Society of Chemistry: Cambridge, UK.

Waterton JC, Pylkkanen L (2012) Qualification of imaging biomarkers for oncology drug development. Eur J Cancer 48(4): 409-415.

Workman P, Aboagye EO, Balkwill F, Balmain A, Bruder G, Chaplin DJ, Double JA, Everitt J, Farningham DA, Glennie MJ, Kelland LR, Robinson V, Stratford IJ, Tozer GM, Watson S, Wedge SR, Eccles SA (2010) Guidelines for the welfare and use of animals in cancer research. Br J Cancer 102(11): 1555-1577.

Yeung DK, Bhatia KS, Lee YY, King AD, Garteiser P, Sinkus R, Ahuja AT (2013) MR elastography of the head and neck: driver design and initial results. Magn Reson Imaging 31(4): 624-629.

This work is published under the standard license to publish agreement. After 12 months the work will become freely available and the license terms will switch to a Creative Commons AttributionNonCommercial-Share Alike 3.0 Unported License. 